\title{
La música y los límites del mundo. Un estudio desde Eugenio Trías y Agustín de Hipona
}

\section{The Music and the Limits of the World. A Study on Eugenio Trías and Augustine of Hippo}

\author{
Diego I. Rosales MeAnA \\ Centro de Investigación Social Avanzada (Querétaro, México)
}

Recibido: 27-02-2012

Aceptado: 11-06-2012

Para Álvaro Lujambio

\section{Resumen}

El objetivo de este trabajo se centra en el papel que adquiere la música en la constitución del mundo como categoría filosófica. Para ello, se explora la obra de Eugenio Trías y Agustín de Hipona y el modo como ambos filósofos han conceptualizado la música en relación con la constitución del tiempo del mundo. Si para Trías la música no apela al mundo sino a sus límites y así lo informa, para Agustín la música pone en contacto al hombre con el ordo del universo, liberándolo así de la distentio animi mundana, y ayudándolo a dar sentido al mundo que se presenta como finito.

Palabras clave: límite, mundo, música, orden, tiempo.

\begin{abstract}
This work focuses on the role that music has in the constitution of the World as a philosophical category. I explore the work of Eugenio Trías and Augustine of Hippo, and the way both philosophers have conceptualized music in relation to the constitution of the time of the World. For Trías music is not about the World but about its limits and, in that way, gives it a form. For Augustine music relates man to universe's ordo, liberating him from mundane distentio animi and helping him to give sense to a World that gives itself as finite.
\end{abstract}

Keywords: Limits, Music, Order, Time, World. 


\section{La noción de 'límite'}

El concepto de 'límite' es para la filosofía de Eugenio Trías uno de sus más importantes eslabones. Es una noción que le ha servido para elaborar un pensamiento que busca comprender el mundo, el sentido del mundo, cuya contingencia siempre está presente. Su ontología permite afirmar de las cosas que son frágiles, que pertenecen a un ámbito de la realidad inscrito en el devenir. El mundo y todo lo que hay en él pertenece al conjunto de cosas que responden a cambios y mutaciones, al conjunto de cosas que no son necesarias del todo.

Dado que los entes y las cosas tienen limitaciones, son finitas, aparecen y desaparecen, entonces podemos decir que el mundo tiene ciertos límites: las cosas tienen un marco mas allá del cual ya no son, a partir del que dejan de ser. Así Trías introduce la noción de "límite", como la frontera última del mundo, de todo lo que existe. Todo límite es siempre límite de algo. Y lo que queda de un lado de la limitación, lo que queda más acá del límite es el mundo mismo, es lo conocido, son las cosas. Esta dimensión, la de adentro, es la casa, el lugar de donde somos los hombres.

Lo "otro" constituye lo que cae fuera del límite. Es la alteridad, lo desconocido. Para los antiguos romanos, por ejemplo, "el mundo tenía, pues, en el limes su frontera, frontera entre razón y sinrazón, entre cultura y naturaleza, entre ley y selva.”1 Así, lo que está dentro del límite es concebido como el mundo, como lo habitado y lo habitable de lo que hay. Lo que está fuera es el mundo de lo bárbaro y lo extranjero, lo desconocido. El límite como tal, sin embargo, participa de los dos lados. Es "conjuntivo", por que une lo de adentro con lo de afuera, pero también es "disyuntivo", pues es precisamente lo que marca la diferencia. El límite es en este sentido identidad y diferencia a la vez.

Hay dos ejemplos que utiliza Trías para explicar la idea del límite, con los que ilustra la pregunta ontológica sobre la relación entre el mundo, lo mundano conocido y la totalidad del ser. El primer ejemplo es la ciudad romana, la antigua urbe. Para los romanos, lo que estaba dentro de las fronteras constituía el mundo propiamente dicho: el mundo en el que el hombre se despliega, la casa y la morada en la que si algo se sucede, sucede de acuerdo con las leyes y las características que están dentro del dominio de lo humano y lo proporcional. Lo que queda fuera es, en cambio, el misterio, es lo extraño, lo que quizás es demasiado grande o demasiado tremendo como para encerrarlo en nuestras categorías de administración, ordenamiento y comprensión. Así era como los ciudadanos romanos y luego los bizantinos concebían las fronteras del imperio. El mundo, identificado con la urbe es, por tanto, el territorio en el que se puede vivir, en el que se pueden hacer cultivos, construir casas, establecer familias y hacer crecer las cosas. "El limes en consecuencia, es un territorio habitable desde el cual se abre la posibilidad del sentido y la significación (logos, pensar-decir). Como tal marca «límites» en relación con el mundo mismo, a lo que desde él se defiende o se pretende preservar, y en relación con lo que, desde fuera de él, lo acosa y cerca."2 Queda así descrito, a grandes rasgos, el mundo como la morada del hombre, como el devenir de la historia en el que los seres humanos comparecen unos a otros y viven sus vidas. Lo otro, en cambio, esta fuera de todo dominio, está fuera del alcance de cualquier miembro del mundo,

\footnotetext{
1 Eugenio Trías, La lógica del límite. Barcelona, Destino, 1991, p.16.

2 Ibid, pp. 20-21.
} 
pero sin embargo se concibe como un horizonte presente, como el fondo permanentemente presente que permite que lo que suceda en casa pueda suceder.

Para Trías hay, pues, una topología ontológica que marca una diferencia entre tres ámbitos, en el medio de los cuales se encuentra el límite. Para explicar esta idea, en Los límites del mundo recurre al ejemplo de "El gran vidrio", la famosa obra de Marcel Duchamp. En tanto cristal, el límite marca la diferencia entre lo que está cada lado pero al mismo tiempo es una frontera traslúcida. De un lado se encuentra el mundo y del otro todo lo que está más allá de los límites del mundo, y que Trías llamará "espacio-luz".

Del primer lado, "todo lo que hay, cuando puede darse o suceder, lo físico, la naturaleza entera, la que habita el cerco o la frontera, se halla determinada por ese límite infranqueable que le permite determinarse como ser finito, despedido de una falta originaria imposible de colmar, y remitido a un «fin sin fin» imposible de cumplir. Hay un hiato en el origen y en el fin: por esa razón el ser es constitutivamente finito."3 Así, lo que está de este lado, lo contingente, lo histórico, es y siempre será finito como condición constitutiva. El mundo es frágil, es quebrantable y resbaladizo. En el mundo las cosas cambian, se suceden unas a otras, sufren metamorfosis y perecen.

A diferencia de como era concebido de acuerdo con la imagen de la ciudad romana, en donde era considerado como lo doméstico, el mundo es aquí concebido, más bien, como lo "brutal" en la medida en que es siempre contingente y frágil, en tanto que es finitud. El mundo es lo precario, necesitado de un fundamento. De acuerdo con esta ontología "trágica", como la llama Trías, el mundo está determinado por el espacio y por el tiempo.

En cambio, del otro lado del límite, en la región que se constituye como fundamento del mundo, en aquello que está más allá de los límites, no hay ni ser ni tiempo, sino que aquello que hay es precisamente fundamento del ser y del tiempo. Así, lo tremendo que está del otro lado del cristal y que se diferencia de lo familiar y por ello también brutal es calificado como el "espacio-luz", pues permite que todo el mundo trasluzca y sea diáfano. Aquello que está más allá de los límites del mundo es lo que posibilita que el mundo aparezca como tal y por eso es luz, y por eso espacio: pues el aparecer solamente puede darse en un espacio iluminado. Así Trías emprende, después de su "ontología trágica", la "segunda sinfonía", en la que se trata de comprender eso que está fuera del límite desde una perspectiva subjetiva y mundana, para lo que hay que pensar las cosas de un modo radicalmente nuevo. Si se trata de ir más allá del límite, hay que emprender incluso un pensamiento basado en un lenguaje y unas categorías distintas, pues aquí ya "ser significa pues, darse a sí mismo un límite que lo separa de lo que absolutamente trasciende. Ese darse a sí mismo un límite hace del ser ser-tiempo. Y el tiempo es ese límite que el ser se da con referencia a un absoluto no darse." 4

Más que lograr dilucidar del todo en qué consisten todos los lados del límite, enumerar -como enlistando un mobiliario ${ }^{5}$ todo lo que hay dentro del límite y todo lo que cae fuera, el objetivo de Trías es comenzar a comprender en qué consiste la diferencia y el papel que

\footnotetext{
3 Eugenio Trías, Los límites del mundo, Barcelona, Ediciones Destino, 2000, p. 313.

4 Ibid, p. 320.

5 Cfr. Jacobo Muñoz, “Experimentum Mundi (Nota sobre la ontología trágica de Eugenio Trías)” en Jacobo Muñoz y Fco. José Martín (eds.), La filosofía del límite. Debate con Eugenio Trías. Madrid, Biblioteca Nueva, 2005, p. 58.
} 
el límite juega en la constitución de un mundo y, claro, también en entrever el sentido de aquello que el límite, que es siempre traslúcido como un cristal, deja pasar y asomarse. "Se va perfilando, a través de este discurso, -señala Trías- un dualismo ontológico (de ámbitos, no de mundos) rebasado y trascendido en un monismo topológico. Ese monismo afirma de lo uno o de lo mismo su naturaleza de diferencia pura, intrínseca (su absoluto autodiferenciarse). El mismo es siempre mismo en su radical diferenciación, eso que puede simbolizarse del modo como anverso y reverso de una sustancia o lámina de vidrio"6. En este sentido, Trías propone leer el mundo desde dos niveles: por un lado, lo que se muestra, las cosas del mundo, el mobiliario de entes. Por otro lado, las condiciones que permiten que eso acontezca, aquello que está más allá de los límites y que va bordeando y, con ello, permitiendo que el mundo surja.

De esta manera, en el limes, en el límite mismo no solamente está en juego qué está aquí y qué está allá, no solamente se trata del trazado de fronteras y del mapeo geográfico de la ontología, sino que en el límite se juega y se debate la cuestión del ser o del sentido del ser. Por eso el despliegue asumirá siempre una forma lógica. Es precisamente aquí que la "estética del límite" "cobra sentido como el primer paso para elaborar una comprensión de lo que se pone en juego entre el mundo, el límite y aquello que está más allá, pues es en el arte que el artista lleva al "límite" las posibilidades de lo sensible, rasgando y arañando con la obra de arte tanto el terreno constituido por el límite mismo, como lo que está fuera de él, haciendo que transluzca por entre el cristal (recordemos la figura de Duchamp) lo que está del otro lado y que da sentido y fundamento a lo que está dentro.

\section{Las artes del límite}

Dentro de la tarea de ir desvelando aquello que es propio de los fenómenos que pertenecen al ámbito de lo sensible, necesitamos comenzar a hablar tanto del mundo como del límite mismo. En este sentido, las artes juegan un papel esencial, pues ellas nos conducen a las fronteras. El arte es la tarea humana que empuja a la creatividad a explorar el mundo y empezar a reconocer sus límites y, por momentos, a traspasarlos. El arte nos conduce a la experiencia que puede indicar en dónde termina y en dónde comienza el mundo. Si en nuestra vida cotidiana nos las habemos con las cosas, con los objetos que utilizamos y que reconocemos de manera normal, el arte es la hipérbole de la cotidianidad, nos saca de esa habitualidad y nos reinstala en el mundo de otro modo: nos obliga a preguntarnos sobre los límites del mundo, sobre el alcance significativo de nuestros hábitos y de todo lo que aparece en ellos. El papel del artes es, entre otros, aclarar o revelar, por una extensión de la experiencia, lo que para el ojo cotidiano queda oculto.

Para ello, habrá que ver, dentro de todas las artes, cuáles son las más primigenias, las artes que exploren no ya el mundo mismo sino el límite del mundo: habrá que ir al quehacer artístico que se despliega en el límite que hace posible que el mundo acontezca. Estas artes tendrán que ser las que no nos hablen de ninguna cosa en concreto, las que no nos refieran a objetos mundanos, tendrán que ser artes que, al contrario, hagan posible que el mundo

6 Eugenio Trías, Los límites del mundo cit. p. 334. 
sea mundo y que los objetos sean objetos; artes que no sean mundo, sino que lo constituyan. Estas artes, que trabajan en el límite, serán artes que en lugar de presentarnos el mundo con representaciones de él, establezcan las condiciones para que ese mundo sea tal. Éstas son, de acuerdo con Trías, la música y la arquitectura, pues gracias a ellas el mundo es susceptible de ser habitado.

Ni la música ni la arquitectura retratan el mundo. Ni la música ni la arquitectura representan o imitan objetos, sino que ambas generan un "medio ambiente" que permite que el mundo surja como mundo, como habitación nuestra. "Para que haya mundo, experiencia del mundo y de los límites del mundo, debe allanarse, formarse y cultivarse antes eso que lo presupone, y a lo que suele llamarse medio ambiente. La música determina y da forma al ambiente, lo mismo que la arquitectura. Ésta da forma al ambiente que se despliega como espacio (o en reposo) mientras que la música determina la forma ambiental que hace posible toda experiencia del movimiento y del tiempo (y de aquello que en el tiempo se despliega, como es la palabra en el tiempo)."7 Espacio y tiempo, las dos coordenadas bajo las cuales nuestra existencia topológica tiene cabida ${ }^{8}$, son los hiatos, los huecos, en los que el hombre habita: espacio y tiempo han de ser domesticados y constituir, así, un medio ambiente y sean entonces una casa para el hombre. El medio ambiente es el límite sobre el cual se hace posible la experiencia del mundo. Sólo cuando hemos construido un medio ambiente podemos decir que hemos habitado el mundo. Antes no. Antes, solo estamos ante una brutalidad selvática e inhóspita, que no permite que el mundo tenga sentido. Mientras que la arquitectura se ocupa de determinar, imponer límites y dar forma al espacio para que éste sea habitable, la música se encarga de dar forma e imponer límites al tiempo, para que podamos estar en él y situarnos en él ${ }^{9}$.

Dado que ambas artes son condiciones del mundo y no propiamente del mundo, también podemos afirmar que ambas artes son, pues, pre-lingüísticas: posibilitan el surgimiento del lenguaje y sus significados, hacen posible que experimentemos las cosas desde un trasfondo: unos anteojos, por ejemplo son tales porque están en un contexto, sobre un trasfondo que hacen que ellos aparezcan siendo lo que son y con la singularidad que les es propia. Así, el hombre, para poder aparecer y surgir en tanto hombre, necesita que espacio y tiempo hayan cobrado una forma determinada: hay que dar al espacio y al tiempo medidas y proporciones adecuadas a la escala del hombre para que éste se sienta en casa. En eso se diferencia el mundo del puro caos.

Adán, quien en el Génesis dota de un nombre a las cosas del mundo, con su actividad bautismal se ha encargado de hacer del mundo un ambiente hospitalario: nombrar es entrar

\footnotetext{
7 Eugenio Trías, Lógica del límite cit. p. 42.

8 Larga es la tradición filosófica que ha dado cuenta del espacio y el tiempo como las condiciones sobre las que acontece el hombre. Por mentar una síntesis innovadora que pone en relación estas condiciones topológicas, es decir, existir en un lugar, con la experiencia de los límites del mundo, es bueno mirar el libro de Jean-Yves Lacoste, Experiencia y absoluto, Salamanca, Ediciones Sígueme, 2010. Traducción de Tania Checchi.

9 Un interesante estudio que pone en relación la música con la arquitectura sobre todo en el período medieval, y que puede servir para profundizar en las relaciones entre arquitectura y música en Trías y Agustín de Hipona, es el de V. Zara, "Music and Architecture between the Middle Ages and the Modern Age- Critical History of an Idea" en Acta Musicologica, v. 77, n.1, 2005.
} 
en una relación familiar con las cosas. Pero para nombrar, es necesario primero que el lenguaje tenga un estatuto significante. $\mathrm{O}$, más precisamente, nombrar las cosas es ir dotando al lenguaje de un significado, pues se establece la primera relación entre el signo (la palabra) y el significado (la cosa). Poner nombre a algo es un modo de apropiarse de él: el nombre es el mejor signo del "hábito". En este sentido, las artes del límite se sitúan en un momento anterior al bautismo del mundo. La música y la arquitectura no son, pues, nombres de nada: permiten que pongamos nombres. 10

Mientras la arquitectura sucede en el espacio, la música sucede en el tiempo, en el devenir: es pura forma del tiempo sin una materia particular. La música trabaja en la frontera del tiempo: "la música es un ininterrumpido fluir temporal abocado a un desenlace fluvial. Sólo en esa desembocadura adquiere la pieza musical su forma, que es forma-en-el-tiempo [...] La música se cumple como entelequia, como pieza concluida y definida, cuando alcanza esa meta final, cuando la cadencia cierra el decurso del fluir musical y remansa el crecimiento y mengua de su caudal acuoso."11 Si no ha terminado, entonces no puede decirse todavía que haya sucedido la música: ésta solamente existe en un lapso de tiempo, mientras es tocada y escuchada y hasta que termina de ser escuchada. La música necesita del tiempo y -a una- lo constituye para el sujeto. En la medida en que la música constituye tiempo y genera, al darle forma, un medio ambiente, es un arte "matricial": un arte que genera, del que puede luego devenir un mundo.

La música es un arte de los principios del mundo y permite que ésta sea habitado porque nos sitúa: nos da un lugar en el tiempo. Cuando en el mundo no hay música, lo que hay es ruido, y el ruido es la selva, es lo inhóspito, aquello en lo que no es propicio vivir. "Del mismo modo como la casa, el castillo, la catedral y su entorno urbano y paisajístico no son, prioritariamente, algo que se da a ver, aunque sí lo sean desde la tradición paisajista-pintoresca (que supone una invasión «moderna» de lo «pictórico-visual» en lo arquitectónicoambiental), asimismo la música no es algo que se da a escuchar, sino algo que se erige como templo, y que se implanta, arraigándose, como hábito, en el oído y que está ahí para ser habitada." 12 Cuando la casa o el edificio o el puente son contemplados como un objeto estético que ha de ser admirado por su aspecto visual, entonces ya no asistimos a lo arquitectónico como tal, sino que estamos considerando a esta casa, a este edificio, o a este puente como una imagen a ser vista, no como arquitectura sino como escultura. Lo arquitectónico mismo es algo que se despliega en su ser-arquitectura, más bien, cuando es habitado: un edificio -desde el punto de vista de la arquitectura como arte del límite- es la habilitación del mundo, no su ornamentación. Con esto no es que apueste por una visión funcionalista de la arquitectura, pues no se trata de "funcionamiento", sino de habitación. Puede perfectamente haber una casa poco o nada funcional, pero al mismo tiempo habitable, en la medida en que ésa permite que tengamos un hogar. También puede darse el caso de que la arquitectu-

\footnotetext{
10 Alfonso Reyes, en su maravilloso ensayo "Hermes o de la comunicación humana" habla de la situación primigenia en la que se encontró Adán cuando tuvo que nombrar a cada una de las especies del paraíso. Para Reyes, esta situación primigenia representa una experiencia límite, anterior a todo acto comunicativo y de origen del lenguaje. Cfr. La experiencia literaria, México, Fondo de Cultura Económica, pp. 9-39.

11 Eugenio Trías, Lógica del límite cit. p. 44.

12 Ibid, p. 48.
} 
ra cumpla con todo: belleza ornamental, funcionalidad y habitación, pero lo propio de la arquitectura se da en el último rasgo, en el de la capacidad de permitirnos habitar el mundo.

De igual modo, considerar la música en lo musical mismo no consiste en escucharla, como si fuera algo externo a nosotros, algo que esté ahí dispuesto sobre la mesa para ser analizado, sino que lo musical mismo se juega en el momento en que nos involucramos con la música, en el momento en el que, propiamente, habitamos la música y hacemos de ella nuestra morada. Solamente así lo musical aparecerá en todo su esplendor, pues consiste en hacer del tiempo no algo externo a nosotros sino una casa, el hogar de nuestra humanidad. La música, pues, no se escucha, sino que se vive en el sentido fuerte del término. ${ }^{13}$

\section{Música, tiempo y límite}

Veamos con detenimiento en qué consiste la música, y veamos si en su definición y en la exploración de su naturaleza, encontramos algún otro rasgo que nos ayude a comprender su relación con los límites del mundo y por qué puede ser caracterizada como un arte que da forma al tiempo.

La materia de la música es el sonido, sin embargo no es mero sonido: es sonido articulado. Lo mismo la palabra hablada en la que se pronuncia un discurso. En la música, sin embargo, no hay un significado primordial que sea transmitido con la articulación de los sonidos. Por otra parte, en la música, aquello que determina la forma y la articulación de los sonidos es un ritmo: una proporción entre un sonido y otro, proporción que tiene lugar solamente a través del tiempo. La música se mide en tiempos. De hecho, la música solamente existe en el tiempo: no existe en el espacio, pues ella no ocupa lugar alguno. La música existe en la medida en que es tiempo y devenir. Así como una obra arquitectónica define el espacio, la música define el tiempo. Por eso, dando forma rítmica a los sonidos, la música impone límites al tiempo "La música significa la posible transformación de esa masa elástica de vibración en sentido (sensorial, emotivo, intelectual). Esa materia vibrante propaga ondas sonoras de variable longitud y frecuencia, y al acogerse en la escucha puede suscitar un sentido que es, o puede ser, a la vez sensorial e intelectual, emotivo y referido a la inteligencia (y a las ideas que ésta propone)."14 La música tiene, pues, sentido, pero no significado. El sentido es la forma misma que lo musical da al sonido y que, sin eso, sería ruido y materia bruta: ya no solo ritmo, sino sentido. Cuando la música ocurre, lo que en realidad ocurre es que el ruido está recibiendo un sentido, un logos, una forma determinada: se le imponen límites al tiempo. Por eso, en Los límites del mundo, Trías llamaba al mundo "lo brutal" pues, a pesar de ser el lugar en el que habitamos, si no recibe una forma se mantiene como lo inhóspito mismo: como un sitio abandonado a la buena del desorden. "Todo lo que hay, cuanto puede darse o suceder, lo físico, la naturaleza entera, la que habita el cerco o la frontera, se halla determinada por ese límite infranqueable que le permite determinarse como ser finito, despedido de una falta originaria imposible de colmar"15, es decir, el mundo es vago

\footnotetext{
13 Cfr. Ibid, pp. 45 ss.

14 Eugenio Trías, La imaginación sonora. Barcelona, Galaxia Gutenberg, 2010, p. 580.

15 Eugenio Trías, Los límites del mundo, cit. p. 313.
} 
y contingente, es mundo caído. Lo que ocurre en el espacio y en el tiempo está lleno de defectos, es un desorden tal que, si no recibe una cierta forma, se mantiene como lo inasible y lo inhabitable. Y esto es algo que también Octavio Paz notó: "El ritmo no solamente es el elemento más antiguo y permanente del lenguaje, sino que no es difícil que sea anterior al habla misma. En cierto sentido puede decirse que el lenguaje nace del ritmo; o, al menos, que todo ritmo implica o prefigura un lenguaje."16 La música, pues, permite que generemos el lenguaje necesario para habitar el mundo, para que comuniquemos las mociones del ánimo y entonces establezcamos relaciones, ya no solamente entre el mundo y el hombre, sino también entre la comunidad de hombres.

Lo que conocemos, todo lo que aparece, el mundo con sus objetos y sus especies, el devenir del tiempo y de la historia constituyen algo principalmente desordenado. Dado que el mundo es contingente y cambiante, no constituye ni puede constituir el fundamento de sí mismo. De acuerdo con Trías, considerado así sin más el mundo necesita domesticación: "el ser es lo absolutamente brutal, es decir, lo que carece de fundamento intrínseco. Éste se halla, por lo que ya he insinuado, fuera del propio espacio de mostración y dicción de lo que hay, un paso allende lo ontológico puro"17, y como está fuera del ámbito de lo que puede ser mostrado, de lo que puede aparecer propiamente ante nuestros ojos, necesita que le sea proveída una forma, un sentido para que podamos, así, habitarlo.

La música transforma el ruido en sonido y el sonido en sentido. No hay en la música, así como en la pintura o en la escultura, un significado concreto. Ellas son artes puramente semánticas, pues el significado está plenamente dado en la obra misma. Para la música no. En ella, si bien el sonido nos aparece vacío de significado -al contrario de las artes plásticas mencionadas-, aparece también completamente lleno y pleno de sentido: en el sentido mismo radica que sea música, y el sentido es siempre comprensible. Esto es lo que explica que una disonancia sea tal: una nota discordante no podría ser discordante si no está presupuesto un sentido. "La música puede promover -a través de la imaginación sonora- la unión simbólica de sensibilidad e inteligencia, de idea (musical) y materia (sonora) sin necesidad de palabras, sintagmas, o construcciones sintácticas que hagan posible la performance de la significación. Las creaciones musicales no poseen significación (según la semántica que deriva de la lingüística) pero rebosan de sentido (según la propia y específica semántica musical)."18 Pero aún cabe preguntar, ¿a qué se refiere Trías con "sentido”? ¿Por qué se puede decir de la música que no tiene significado pero sí sentido? ¿Cómo puede la música referir a algo (intencionalmente, por ejemplo) -tener sentido- si no hay significados presentes en el fenómeno?

Como habíamos señalado, el mundo es por principio carente de forma, es una hueste de eventos aleatorios, imposible de habitar. Necesitamos por ello de las artes del límite: que otorguen forma habitable y hagan del mundo un lugar hospitalario. Eso es precisamente el sentido. La música, en tanto arte del límite, provee al mundo de un sentido en la medida que el límite va trazando las fronteras de lo habitable y lo inhóspito, y deja traslucir en ella y en su devenir, algo de lo que está más allá de los límites del mundo. La música es, por ello, un evento, un acontecimiento que, ocurrido en el tiempo siempre de manera irrepetible (aun-

\footnotetext{
16 Octavio Paz, El arco y la lira. México, Fondo de Cultura Económica, 1982, p. 68.

17 Eugenio Trías, Los límites del mundo, cit. p. 317.

18 Eugenio Trías, La imaginación sonora, cit. p. 581.
} 
que la 5a sinfonía de Beethoven es estructuralmente una, cada vez que se reproduce es, al mismo tiempo, siempre diferente, a diferencia del cuadro o la escultura, que se mantienen siempre los mismos), dota de sentido al presente y saca al sujeto de su estar distendido en el tiempo. "El artista es, pues, el desvelador práctico y productivo, o el héroe ético y moral, activo y ejecutivo que promueve la visión resplandeciente de la línea o de la bisagra, que es la verdad de todo ser o suceder."19

Como arte del límite, la música no puede referir al mundo, necesita apelar a algo más allá de él. No es un arte mundano, no es tampoco del mundo. Si bien su materia, el sonido, es parte del mundo, la forma y el sentido que da no pueden provenir de él. En la medida en que de hecho la música permite generar una "habitación", la música está en el límite del mundo dejando entrever aquello que está más allá de los límites ${ }^{20}$.

Es claro, por otra parte, que la música también podría abandonar su tarea de dar sentido y constituirse en arte mundano. Eso puede suceder, no hay nada que lo impida. Cuando la música toma como referente las cosas y habla de ellas y transmite significados concretos, entonces se está situando en un plano más acá del límite. No es que deje de ser música, sino que únicamente se sitúa en un plano mundano, aunque la posibilidad de constituirse en arte del límite y separarse del mundo nunca desaparece, tal como lo veremos en Agustín, cuando distingue la música como arte liberal de la música como quehacer meramente técnico (música de uso). Pero incluso la música vocal puede situarse en el plano de las artes limítrofes, pues en ella se mantiene válida la idea de que en la música el significado no está presente: "las notaciones musicales no trabajan signos lingüísticos sino diseños motívicos o temáticos que traman entre sí relaciones de altura, o relaciones dinámicas, de velocidad, intensidad, fuerza, y que circulan entre las distintas voces (en composiciones que rebasan el cantus firmus), componiendo complejos tejidos armónicos, rítmicos, melódicos y compositivos." 21

La música, entonces, es el arte que trabaja con los sonidos, otorgándoles una estructura de sentido comprensible y, con ello, dota al tiempo de una forma. Sin música, el tiempo se disuelve en la historia: en presente, pasado y futuro. Mucho se ha dicho sobre el tiempo, pero uno de los problemas principales para comprender su naturaleza es que se intenta explicar con categorías no temporales sino espaciales. En ese sentido, pensamos que el pasado está "atrás" el presente "aquí" y el futuro "adelante", como si el tiempo fuera el transitar por una recta numérica. Eso es precisamente el tiempo salvaje. El tiempo es inhóspito cuando se nos presenta como un tiempo en el que podemos perdernos, o como un objeto a administrar, como si el tiempo fuera un objeto que pudiéramos perder. Cuando vivimos bajo la conciencia de un tiempo objetivo, que hay que medir, controlar y aprovechar, entonces estamos ante un tiempo inhóspito, salvaje, que aún no ha cobrado su verdadera forma: pues cuando eso ocurre, entonces no estamos propiamente en casa. La única forma de que podamos perdernos en el tiempo es que éste tenga huecos vacíos, escondites, lugares, es decir, que sea espacio. Un tiempo habitable, en cambio, es un tiempo imperceptible: un ocurrir sin conciencia de que ocurre. Cuando estamos en casa, ni siquiera nos damos cuenta de que

19 Eugenio Trías, Los límites del mundo, cit. pp. 341-342.

20 Cfr. Eustaquio Barjau, "La música en la obra de E. Trías" en Jacobo Muñoz y Fco. José Martín (eds.) Op. cit. pp. 237-255.

21 Eugenio Trías, Lógica del límite, cit. p. 53. 
estamos en casa: simplemente habitamos. Por ello cuando medimos el tiempo no lo estamos habitando. Un tiempo habitado es un tiempo no medido, es un tiempo no percibido, es decir, es puro presente. Cuando expandimos el tiempo hacia atrás y hacia adelante y comenzamos a medirlo, entonces estamos ante la forma inhóspita de él. Y nos perdemos. Para que el tiempo sea habitables es, pues, necesario, salirnos del tiempo y que permanezca -igual que el espacio domesticado- como una condición que permite que la vida tenga lugar.

Para comprender estas ideas sobre la música de mejor manera, y así profundizar en la pregunta filosófica sobre ella puede constituir el sentido del mundo, me atrevo a incursionar en algunas de las ideas más importantes de San Agustín. Me parece que las categorías agustinianas, si bien lejanas en el tiempo a la filosofía de Eugenio Trías, pueden ser de utilidad también para comprender las relaciones entre la música como una proporción armónica que sucede en el tiempo y el papel que ésta juega en la transformación del mundo en un lugar habitable para el hombre.

\section{Tiempo y orden del mundo en San Agustín}

La filosofía agustiniana está, como todas las filosofías, llena de complejidades. En su caso particular, las complejidades residen, en primer lugar, en que la distinción o diferencia entre teología y filosofía era prácticamente inexistente. En segundo lugar, Agustín suele hacer filosofía de modo asistemático. Si bien hay algunos grandes tratados en su haber, su estilo suele ser más apasionado y dialógico que calculador y lineal. Su obra se desarrolla discurriendo sobre varios temas y con más bien poca exactitud en el momento de utilizar algunos términos técnicos. Considerando estas dificultades, mostraré a continuación, algunos de los aspectos más importantes de la filosofía platónica y neoplatónica de la que se vio influenciado San Agustín en lo que respecta a sus ideas sobre la música y el tiempo y, luego, algunas de las ideas básicas del mismo Agustín sobre la música y el ordo bajo el que está constituido el cosmos. De este modo intentaremos aclarar las posibles confluencias del pensamiento del hiponense con las ideas de Trías y, así, contribuir a pensar la música misma como un arte del límite, configuradora de mundo.

\subsection{El ordo agustiniano y sus antecedentes neoplatónicos}

Para los platónicos hay un orden del mundo que emana del perfecto Uno, del sumo Bien. Toda la creación depende de este Bien perfecto. Toda la creación es, pues, un bien imperfecto. Este Uno es aquello de donde emanan todas las cosas y hacia donde todo ha de retornar. El mundo entero está, pues, en constante devenir, en un movimiento que ha nacido de este Bien perfecto y que ha de terminar en el retorno, en el camino de vuelta y en el reencuentro con él.

Este movimiento de salida y de vuelta, esta emanación del Uno por la que han venido a ser todas las cosas a través del tiempo, genera el mundo entero y explica la jerarquía ontológica y los diferentes estratos o hipóstasis del Uno ${ }^{22}$. Así, la vida del alma (aunque antes el

22 Cfr. Juan David García Bacca, Introducción general a las Enéadas. Buenos Aires, Editorial Losada, 1948. 
entendimiento, que para los neoplatónicos es algo superior al alma) también consiste en el esfuerzo de ella para volver al Uno primigenio del cual ha emanado, con lo que el hombre vive en una lucha a muerte con la materia, intentando emanciparse de ella para volver al Uno generador. Todo el cosmos y toda la creación está en ese desfile, la vida y la historia es una danza que consiste en generar los ritmos necesarios y adecuados para que todos los seres vuelvan a incorporarse al lugar del que han venido, y el arte aquí juega un papel importantísimo: "el arte -explica Trías acerca del neoplatonismo-, en tanto producción de obra iluminada por la idea intelectual en donde se refleja el rayo de belleza, constituye un orden privilegiado en el cual esa guerra se produce: guerra de reconquista en la cual quiere el alma ganar para las hipóstasis superiores la materia, elevar ésta hasta la luz."23 Por eso, en la medida en que el arte es material, se aleja de la meta principal, que es desembarazarse de lo contingente, de la violencia que la materia ejerce sobre lo espiritual. Así, si la música es un arte, precisamente, formal, cuyo elemento material es mínimo constituido por el sonido, será un arte mucho más perfecto, un arte espiritual, pues no transmite, como lo señalamos antes, ningún significado material del mundo, sino que da una estructura y una forma a los límites del mundo: el tiempo mismo.

La belleza es, en este sentido, un vehículo de ascensión hasta el Uno del que depende todo lo que existe y todo lo que pueda existir. ${ }^{24}$ Así también, para San Agustín, el mundo está estructurado de acuerdo con un orden, en el que Dios ocupa el lugar del más perfecto como summum bonum y al que todos los seres del mundo le deben el ser ${ }^{25}$. En su tratado Del orden, escrito en forma de diálogo, Agustín sostiene que todas las cosas existen bajo un orden: "¡cómo se relacionan entre sí en el universo todas las cosas y con qué ordenada sucesión van dirigidas a sus desenlaces!'26 Para Agustín todas las cosas fueron creadas por Dios, que es el sumo Bien, de donde se sigue todas las cosas son también buenas. Sin embargo, hay en ellas grados de perfección, por su semejanza con Dios: "Dios está sobre toda medida de la criatura, sobre toda belleza y sobre todo orden, no con superioridad local o espacial, sino con un poder inefable y divino, porque de él procede toda medida, toda belleza, todo orden. Donde se encuentran estas tres cosas en grado alto de perfección allí hay grandes bienes; donde la perfección de esas propiedades es inferior, inferiores son también los bienes; donde faltan, no hay bien alguno. De la misma manera, donde estas tres cosas son grandes, grandes son las naturalezas; donde son pequeñas, pequeñas o menguadas son también las naturalezas, y donde no existen, no existe tampoco la naturaleza. De ahí se conclu-

\footnotetext{
23 Eugenio Trías, Lo bello y lo siniestro. Barcelona, Seix Barral, 1982, p. 50.

24 Esta idea de la belleza como un vehículo, ya sea por vía dialéctica, o por vía erótica, hacia el ente más perfecto, ya se encuentra en Platón, para quien todo emana del Uno-Bien, la idea de las ideas. Sobre este tema hay dos trabajos que, a pesar de su antigüedad, siguen siendo importantísimos e insoslayables. Sobre Platón, el de Léon Robin, La théorie platonicienne de l'amour. Paris, Presses Universitaires de France, 1964. Sobre Plotino, el de René Arnou, Le désir de Dieu dans la philosophie de Plotin. Paris, Librairie Félix Alcan, 1920.

25 Cfr. Agustín de Hipona, La trinidad V, 2, 3. Obras Completas V. Madrid, Biblioteca de Autores Cristianos, 1985. Traducción de Luis Arias.

26 Agustín de Hipona, Del orden, I, 5, 14. Obras Completas I. Madrid, Biblioteca de Autores Cristianos, 1946. Traducción de Victorino Capanaga.
} 
ye que toda naturaleza es buena." 27 Hay entonces tres características que asemejan y a las vez marcan diferencia entre las cosas a Dios: medida, belleza y orden. Y es respecto de esas características que el universo tiene una estructura marcada intencionalmente hacia Dios, pues en la medida en que participan de la medida, la belleza y el orden, no solamente son cosas, sino que refieren su origen y el punto hacia el cual han de dirigirse.

De esta manera, tanto para la metafísica neoplatónica como para San Agustín, "el arte tendría, pues, la significación de un fomento de reconversión de los objetos materiales a su principio espiritual, una liberación de las cadenas que encarcelan a los seres al mundo en sombras de la materia, una redención de la cautividad en que los seres se hallan cuando viven de espaldas a los rayos solares."28 Igual que para Trías el artista es el que muestra los límites del mundo comunicándolo con lo que está más allá del límite, haciendo del límite vidrioso un diáfano cristal, y proveyendo así al mundo de un sentido, la belleza para los neoplatónicos y para Agustín es una de las vías más claras por las cuales el hombre vuelve a ponerse en contacto con el sumo Bien, con Dios, que fue el creador del mundo y de la historia. Si para Trías el mundo es histórico y caótico en sí mismo hasta que le son impuestos límites en el espacio y en el tiempo, para Agustín el mundo es también un sitio en el que el hombre es un forastero, a menos que se relacione con él y lo habite siempre con miras al origen del que todas las cosas provienen.

\subsection{La armonía y los números en el tratado De musica}

En su tratado De musica, de grande influencia para el neoplatonismo renacentista, Agustín habla de los números que existen en la armonía del universo y de cómo esos números están también presentes en el alma. Si el mundo está estructurado bajo un orden, ese orden es eminentemente matemático. Si bien esto no es una novedad, pues ya los pitagóricos y Platón habían desarrollado una concepción del mundo en el que el cosmos debía su orden a una estructura matemática, con Agustín esta estructura se debe a Dios y, se ve reflejada en la interioridad del hombre, en el alma misma. Para Agustín, dado que el hombre es imagen de Dios, en el alma se pueden reconocer potencias y capacidades análogas al modo como se despliega el ser de Dios en la trinidad. 29

En primer lugar, hay que decir que la música es definida por Agustín como "la ciencia de modular bien" 30 y, al examinar la definición, señala que "modular" viene de modus, que quiere decir medida. Así, la modulación consiste en pronunciar, de acuerdo con cantidades

\footnotetext{
27 Agustín de Hipona, La naturaleza del bien, III. Obras Completas III. Madrid, Biblioteca de Autores Cristianos, 2009. Traducción de Mateo Lanseros O.S.A.

28 Eugenio Trías, Lo bello y lo siniestro, cit. p. 51.

29 Cfr. Agustín de Hipona, La trinidad, cit. XIV, 4, 6. "Ni será imagen de Dios la trinidad que ahora no existe, ni es imagen de Dios aquella que entonces no existirá; es en el alma del hombre, alma racional e intelectiva, donde se ha de buscar la imagen del Creador, injertada inmortalmente con su inmortalidad." Sobre este tema, es bueno ver el formidable artículo de Alfonso López Quintás, "La música, símbolo de la Trinidad. Consideraciones a propósito de una obra extraordinaria" en Pensamiento. Revista de investigación en información filosófica, v. 54, (n.210), 1998, pp.443-447.

30 Agustín de Hipona, La música, I, 2, 2. Obras Completas XXXIX. Madrid, Biblioteca de Autores Cristianos, 1987. Traducción de Alfonso Ortega.
} 
y números proporcionados, ciertos versos y ciertos sonidos: "no incongruentemente se define la modulación como una cierta habilidad de movimiento, o con toda seguridad aquello de lo que resulta que algo se mueve bien." 31 ¿Cómo definir si algo se mueve bien o no? ¿Cómo saber si los movimientos del danzante, del cantante, o del citarista son movimientos armónicos, adecuados y rítmicos? La respuesta surge si ponemos en relación la idea de armonía con la idea de "orden”, ya explicada: si las cosas están destinadas a volver al summum bonum, entonces el movimiento armonioso de ellas corresponderá al ritmo que requieren para volver a ese origen. El ritmo que requieren está, pues, marcado también en la creación misma: el cosmos y el universo están estructurados de manera armónica con base en relaciones numéricas de proporcionalidad, que se ven reflejadas en el tamaño y las proporciones de nuestras extremidades, en el ritmo de la respiración, y también en los ritmos de reproducción de los animales, en el sucederse de la noche y el día, las estaciones y el nado de los peces. Así todos los movimientos que acaecen en el mundo, están regidos por una armonía que pone en relación a todos los elementos del mundo con aquello que les ha dado el ser. "Porque lo que nos detiene y aparta de caminar a pasos desiguales, de dar golpes a intervalos desiguales o de comer o de beber con desiguales movimientos de mandíbulas, o de rascar, en fin, con desiguales idas y venidas de uñas, y para no recorrer con el pensamiento otras muchas operaciones, todo cuanto en cualquier intención de realizar una cosa, por medio de los órganos de nuestro cuerpo, nos aleja de los movimientos desiguales y en silencio nos manda una cierta armonía, es esto mismo precisamente no sé qué juicio, que sugiere a Dios como creador de todo ser viviente: Él es, debemos creer ciertamente, el autor de toda armonía y de toda concordia."32 Pero el giro agustiniano no termina ahí: no es solamente que haya en el universo una determinada armonía universal, una determinada proporción matemática y una gradación de los seres que va de lo más perfecto a lo más imperfecto, sino que todo eso tiene un reflejo y una correspondencia al interior de la subjetividad humana.

Todos los números y las armonías bajo las cuales se mueven y se comportan los diversos entes en el devenir de la historia, los números eternos, tienen un correlato en el alma, a los que Agustín llama, "las armonías de las almas" y que se dividen en cinco géneros, que también van del menos perfecto al más perfecto: 1) los números sonoros, 2) los números sentidos, 3) los números de la memoria, 4) los números proferidos y 5) los números de juicio. Así, en esta "fenomenología de los números", Agustín clasifica el modo como aparecen los números en la naturaleza, desde su dimensión más objetiva y cuantitativa, hasta cómo se constituyen éstos para la conciencia y la subjetividad, pasando por los actos del lenguaje y los números por los que recordamos, descubriendo en el análisis la presencia de ciertas armonías que, aún estando presentes al interior de la subjetividad, son independientes de ella pues no mutan, con lo que son analogables a las armonías eternas. Así, vemos en el De musica:

D. -También esto se puede, a mi parecer, porque aunque se haya olvidado una cosa, puede volver a la memoria, si se le hace recordar por medio de preguntas.

M. - Asombrosa cosa es si piensas que tú puedes recordar, con tal que te pregunte alguien, qué es lo que comiste hace un año.

31 Ibid. I, $2,3$.

32 Ibid. VI, 8, 20. 
D. -Confieso que no puedo, ni creo que al fin que, a fuerza de preguntas, se le haga recordar a aquel otro la cantidad de las sílabas cuya duración ha olvidado enteramente.

M. -¿Por qué es esto así sino porque en el vocablo Italia, por decir un ejemplo, la primera sílaba era breve por voluntad de unos hombres y ahora se alarga por voluntad de otros? Pero que uno y dos no sean tres y que dos no sea el doble de uno, ninguno de los que están muertos pudo, ninguno de los vivientes puede, ninguno de los venideros podrá hacerlo. 33

Estos números que son eternos y de los que depende la proporcionalidad de todo ritmo, de todo canto y de todo verso, tienen un paralelo en el alma, o hay en el alma humana una capacidad estructurada de acuerdo con estos mismos y estas mismas proporciones, de suerte que es esta capacidad la que hace al hombre capaz de reconocer un ritmo. Estos números interiores son llamados por Agustín "números de juicio", pues son los que dan al sentido innato del ritmo la capacidad de juzgar.

M. - ¿De dónde piensas viene a ocurrir que toda una multitud, carente de ciencia, desapruebe muchas veces a gritos a un flautista que emite mala música, y a su vez, aplauda al que toca bien, y precisamente cuando con más dulzura se oye tocar al músico, con tanta mayor elevación y placer se emociona la gente? ¿Habrá que pensar que el vulgo reacciona así de acuerdo con las normas del arte musical?

D.-No.

M. - ¿Por qué, pues?

D. -Pienso que ocurre esto a causa de la naturaleza, que a todos otorgó el sentido del oído con que se juzgan esas diferencias [...]

M.- [...] Así, pues, cuando la memoria sigue al sentido, y las articulaciones, ya cultivadas y entrenadas por el ejercicio, obedecen a la memoria, el flautista, cuando lo desea, toca tanto mejor y más agradablemente cuanto él aventaja en todos aquellos dones que, según nos enseñó antes la razón, tenemos en común con los seres irracionales; es decir, el gusto de la imitación, el sentido y la memoria. ${ }^{34}$

Así pues, hay en San Agustín una correspondencia entre las armonías eternas que están en Dios y las armonías o números del juicio, que están en el fondo de la interioridad humana. La música, entonces, será no solamente un arte y una ciencia en el sentido clásico de ambos términos. Arte en tanto capacidad para modular bien, y ciencia en cuanto que se tiene el conocimiento de la modulación en sí, sino que incluso desde las categorías agustinianas, la música podría ser comprendida como un arte del "límite", pues pone en contacto a lo más íntimo del alma humana con las proporciones armónicas respecto de las que están hechas todas las cosas. Si para Trías la música es un arte del límite porque, en el translucir del límite, permite habitar el tiempo, para Agustín la música es un puente entre el hombre y Dios. Porque si bien para Agustín el mundo no es la verdadera casa del hombre en el sentido paulino, sí lo es en la medida en que esté bien domesticado, y la música y las artes, en la medida en que conducen al hombre a su verdadero fin, cumplen con el trascendente propósito de ordenar a la creación respecto de su fin último.

\footnotetext{
33 Ibid. VI, 12, 35.
}

34 Ibid. I, 5, 10. 


\section{Distentio animi, música y eternidad}

Hemos visto, entonces, que la música puede ser comprendida como un arte del límite. Desde las categorías de Trías esto significa que es un arte que hace del mundo un hogar. Si hay dos dimensiones que han de ser domesticadas para que el hombre tenga un mundo habitable, la música se hace cargo de una de ellas: del tiempo. La arquitectura ofrece la domesticación del espacio y de las condiciones corporales y físicas del hombre, para que pueda tener un suelo y una casa. La música, en cambio, sucede en el tiempo. Si pensamos esta realidad desde categorías agustinianas, vemos que la música pone en contacto al hombre con la armonía y las proporciones del universo. Esto sucede a través del reconocimiento por parte del hombre de ciertas verdades matemáticas que permanecen siendo las mismas sea quien sea quien las piensa. Esto quiere decir que son verdades que están más allá del devenir de la historia y que, aún más, la fundamentan: pues un acontecimiento artístico que sucede en el mundo es comprensible para el hombre en el medida en que responde a las proporciones dictadas por el ordo bajo el cual fue creado el mundo. De este modo, la música coloca al hombre en relación con lo que está más allá del tiempo. O, para decirlo con Trías, con lo que está más allá de los límites del tiempo. ¿Cómo es esto posible?

Anteriormente, al definir la música, veíamos que su materia es el sonido, pero que se diferencia de, por ejemplo, las palabras, en la medida en que, por un lado, carece de significado (no remite a nada del mundo) y, por otro, lo hace con un ritmo y una proporción armónicas. ¿Cómo es que la música da forma al tiempo ${ }^{35}$ ? Para contestar esta pregunta tenemos, pues, que echar mano de las categorías que Agustín nos ofrece en su filosofía pues si el tiempo es algo meramente objetivo, el transcurrir de los objetos que están allí afuera de nosotros, entonces sería imposible darle forma: el tiempo sería un objeto más del mundo. Pero aún en ese caso, estaríamos comprendiendo el tiempo en términos espaciales, como si estuviera extendido sobre un plano, y pudiéramos medirlo y cuantificarlo. Estaríamos comprendiendo el tiempo a lo cartesiano, a lo modernamente cartesiano. Y es cuando comprendemos el tiempo así, a la manera mundana, que nos extraviamos en él, porque pensamos que es un objeto que hay que controlar y medir. En realidad, el tiempo es una forma de la subjetividad pero no espacial. Si el tiempo no es algo, es precisamente espacio. En el tiempo no hay tamaños ni medidas ni huecos ni partes.

\footnotetext{
35 Una respuesta plena a esta pregunta requerirá un abordaje desde dos ámbitos: por un lado la relación de la música con la experiencia fenomenológica del tiempo y, por otro, la relación de la música con el lenguaje y los contenidos semánticos que ésta pudiera transmitir. En este trabajo me concentro en la primera cuestión, que ha de ser respondida antes que la primera pues no podríamos esclarecer la cuestión de los contenidos semánticos sin antes aclarar la más básica cuestión de la experiencia del tiempo vivido, pues todo contenido semántico se da bajo una forma y en un tiempo, siendo el tiempo una instancia previa al contenido semántico. Para la cuestión sobre el lenguaje, recomiendo revisar: Jackson B.D.: "The Theory of Signs in St. Augustine's De doctrina Christiana" en Revue d'Etudes Augustiniennes, v. 15 (n.12), 1969, pp. 9-49; Ando, C. "Augustine on Language" en Revue des Études Augustiniennes, v. 40, 1994, pp. 45-78; Ganzarolli de Oliveira Joao, "San Agustín: lenguaje y alegoría" en Revista agustiniana, v. 42 (n.127), 2001, pp.263-275. Un tratamiento más introductorio de la cuestión puede encontrarse en: Kirwan, Ch. "Augustine's Philosophy of Language” en Stump, E. \& Kretzmann N. (eds.), The Cambridge Companion to Augustine, Cambridge, Cambridge University Press, 2001, pp. 186-204.
} 
En el libro XI de las Confesiones, Agustín ataca frontalmente esta cuestión. De hecho, la pregunta por el tiempo se torna en paradoja en la mayor parte del análisis agustiniano precisamente porque lo comprende con categorías espaciales: "si, pues, hay algo de tiempo que se pueda concebir como indivisible en parte, por pequeñísimas que éstas sean, sólo ese momento es el que debe decirse presente; el cual, sin embargo, vuela tan rápidamente del futuro al pasado, que no se detiene ni un instante siquiera. Porque, si se detuviese, podría dividirse en pretérito y futuro, y el presente no tiene espacio alguno."36 Pero es cuando utiliza estas metáforas espaciales que no cesa de caer en aporías para explicar la naturaleza propia del devenir temporal, y no sino hasta que identifica al tiempo con el alma misma que no puede salir de los atolladeros. Así, el tiempo no puede ser espacial, pues si el pasado ya no es y el futuro aún no lo es y lo único que puede ser es el presente y éste no tiene espacio, entonces debemos comprender el espacio bajo otros términos. Al final, parece quedar claro a Agustín que el tiempo no es ni puede ser una cosa, no es un objeto, sino una forma de la subjetividad misma: "lo que ahora es claro y manifiesto es que no existen los pretéritos ni los futuros, ni se puede decir con propiedad que son tres los tiempos: pretérito, presente y futuro; sino que tal vez sería más propio decir que los tiempos son tres: presente de las cosas pasadas, presente de las cosas presentes y presente de las futuras. Porque estas son tres cosas que existen de algún modo en el alma y fuera de ella yo no veo que existan"37, de modo que el tiempo es precisamente la forma auténtica de la existencia del yo, y lo que parece que es tiempo distendiéndose en la historia hacia adelante y hacia atrás no es otra cosa que el yo mismo, desintegrándose y disolviéndose en el mundo, el yo haciéndose un objeto mundano, lo que implica espacialidad y falta de unidad: "He aquí que mi vida es una distensión [distentio]. Y me recibió tu diestra en mi Señor, en el Hijo del hombre, mediador entre ti -unoy nosotros - muchos-, divididos en muchas partes por la multitud de cosas, a fin de que coja por él aquello en lo que yo he sido cogido, y siguiendo al uno sea recogido de mis días viejos, olvidado de las cosas pasadas, y no distraído en las cosas futuras y transitorias, sino extendido en las que están delante de nosotros; porque no es por la distracción, sino por la atención, como yo camino hacia la palma de la vocación de lo alto."38 Esto es justamente la distentio animi en la que el hombre recae cuando se distrae del presente por la nostalgia del pasado o por el ansia del futuro, dejando de vivir así su propia vida en el presente y disolviendo la unidad que le es propia.

\footnotetext{
36 Agustín de Hipona, Confesiones, XI, 15, 20, Obras Completas II, Madrid, Biblioteca de Autores Cristianos, 2005. Traducción de Angel Custodio Vega O.S.A.

37 Ibid. I, 20, 26. Es imposible en este momento no hacer referencia, al menos, a dos filósofos que después de Agustín han tematizado el tiempo. El primero de ellos es Kant, para quien el tiempo constituía no una categoría sino una de las formas bajo las cuales se constituye la sensibilidad, como suceso en el mundo. El otro filósofo, que asumió la perspectiva agustiniana de manera mucho más radical, es Edmund Husserl, para quien el tiempo objetivo no será más que una proyección intencional del tiempo subjetivo, el único tiempo verdaderamente real. De hecho, para Husserl la forma más originaria de la subjetividad trascendental no será sino tiempo puro. Un interesante estudio, sobre la influencia del análisis agustiniano del tiempo en la filosofía moderna y contemporánea es la introducción que Agustín Corti preparó para la edición del libro XI de las Confesiones en: Agustín de Hipona, ¿Qué es el tiempo? Libro XI de las Confesiones. Madrid, Editorial Trotta, pp. 9-36. Relaciona los análisis agustinianos con la filosofía moderna e incluye una interesante recopilación bibliográfica.
}

38 Agustín de Hipona, Confesiones, cit. XI, 29, 39. 
Es aquí en donde la música adquiere un papel muy particular. Si ésta da forma y domestica al tiempo es porque evita que éste se vuelva espacio. El tiempo inhóspito es aquel en el que nos sentimos extraviados. De este modo, la música permite que salgamos del tiempo, o que vivamos el tiempo como éste exige que sea vivido por nuestra humanidad subjetiva: volcados al presente. La música permite la revelación de lo que está más allá del límite y pone en contacto al hombre con su origen porque permite que el hombre se sitúe en un momento del tiempo. Disueltos en pasado y futuro, en la vida cotidiana, dejamos nuestro lugar propio, abandonamos el lugar con nuestras ocupaciones y nuestras administraciones de la vida. El desasosiego frente a la proyección de un futuro imprevisto, o frente al recuerdo de un pasado insalvable son producto de una objetivación del tiempo, y es la música el elemento que colabora a reinstaurar al hombre fuera de su disolución en tiempo y a reintegrar la subjetividad en el ahora. Cuando en nuestra vida tenemos que habérnoslas con el tiempo y el espacio, preguntarnos en dónde estamos y en qué momento estamos, significa que aún no habitamos verdaderamente. Pero nos dice Agustín:

M. -Así, pues, ¿hacia dónde piensas que deberá moverse ese hombre para que estos números se graben en su espíritu y produzcan aquella disposición sensible que se llama arte? ¿Se los suministrará al menos quien le hace las preguntas?

D. -También él, pienso yo, actuará en su propia interioridad para comprender que las cosas preguntadas son verdaderas y dar respuesta sobre ellas. 39

La música conduce al hombre a su interioridad y, a través de ella, lo lleva a sobrepasar los límites del mundo ${ }^{40}$. La música elimina, en un sentido, el tiempo, y sitúa al hombre en una dimensión extratemporal y extraespacial. Por eso la música permite que habitemos el tiempo ${ }^{41}$. Por eso la música es generadora de ambientes utilizando el tiempo, ajustándolo, enseñándole sus limitaciones, dándole forma de acuerdo con una proporción y una armonía que son siempre más grandes que el hombre mismo, pero que al mismo tiempo se encuentran en su interioridad subjetiva. "Por eso - dijo San Agustín- la generosidad de Dios otorgó a los mortales, que tienen almas racionales, la música, es decir, la ciencia o sensibilidad para modular bien, a fin de enseñarnos una gran cosa. El artista que compone un cántico sabe qué tiempos dé a cada voz para que su canción se deslice y corra bellamente en sonidos que cesan, preceden y suceden. Con mejor motivo, Dios no permite que vayan pasando con mayor prisa o lentitud que la exigida por una modulación prevista y predeterminada los espacios temporales en las naturalezas que nacen o mueren. Como las sílabas y las palabras, son partículas de este siglo en el admirable cántico de las cosas que pasan. Es que la sabiduría divina, por la que fueron creadas todas las cosas, es muy superior a todas las artes. Todo esto podría decirlo yo de la hoja del árbol y del número de nuestros cabellos. ¿Cuánto

\footnotetext{
39 Agustín de Hipona, De musica, cit. VI, 12, 35.

40 Cfr. Agustín Uña, "Pulchritudinis leges. Interioridad y orden en el ejemplarismo estético de san Agustín" en La Ciudad de Dios, v.208, 1995, pp. 849-882.

${ }^{41}$ En un interesantísimo libro, Jean-Louis Chrétien habla -entre otros actos de palabra- del 'canto' en San Agustín. Señala ahí que el canto no es sino una exteriorización de la interioridad, en la que el espíritu se distiende. Cfr. Jean-Louis Chrétien, Saint Augustin et les actes de parole. Paris, Presses Universitaries de France, 2010, pp. 149ss.
} 
mejor podré decirlo del nacimiento y muerte de los hombres, cuya vida temporal no se abrevia o prolonga más de lo que Dios, organizador de los tiempos, sabe que conviene al orden del universo?"42

\section{Agustín y Trías: la música y los límites del mundo}

La música es el arte que deja translucir aquello que está más allá de los límites del mundo. La música sitúa al hombre en una dimensión atemporal, pues el pasado y el futuro dejan de existir mientras la música sucede. Y encontramos aquí uno de los goznes entre la filosofía agustiniana y el pensamiento del filósofo español: "el arte -señala Trías-, en tanto producción de obra iluminada por la idea intelectual en donde se refleja el rayo de belleza, constituye un orden privilegiado en el cual esa guerra se produce: guerra de reconquista en la cual quiere el alma ganar para las hipóstasis superiores la materia, elevar ésta hasta la luz."43 La música es una producción humana, es fruto de un esfuerzo y de una actividad disciplinada pero, tanto Trías como Agustín, insisten en que no cualquier música puede constituirse en un arte del límite, sino que se requiere en ella la presencia de un lógos, de una ratio que le dé proporción al los ritmos y a los sonidos, o que reconozca los ritmos previos del universo y se ajuste a ellos. La noción de música que en Agustín es considerada ciencia, y arte liberal como tal, distinguiéndola de la música popular o 'de uso', para Trías es esta "producción de obra iluminada por la idea intelectual": es producción de ritmo conforme con una idea lógica. De este modo la música se produce no solamente en el contexto de una actividad lúdica y creativa, sin interés alguno, sino que requiere de una ascesis, de un sometimiento del espíritu a ciertos limites o, más bien, limitaciones, para poder dirigir el espíritu hacia esas armonías universales, proporcionales, que permiten que el tiempo sea domesticado. Por eso Trías habla de una guerra en la que el hombre intenta superar al mundo trazando sus límites, primero encontrándolos y luego asomándose más allá del cristal diáfano para así entrever al menos algo de la luz que desde ese lado de los límites le son entregados al mundo. En este punto precisamente, encontramos una similitud con Agustín, que describe este fenómeno de traspasar los límites en su tratado De musica: "por el espíritu sirvo a la ley de Dios, mas por la carne a la ley del pecado (Rom 7, 25). Pero si el alma se suspende en las cosas espirituales y queda en ellas fija y manteniendo su morada, también se quebranta el asalto de ese habitual trato y, dominada su presión, se va extinguiendo poco a poco. Porque era más poderoso cuando íbamos tras él; y si bien no desaparece por completo, es ciertamente menor cuando le ponemos freno, y de esta suerte, por medio de alejamientos seguros ante toda clase de movimiento lascivo, en el que comienza el eclipse de la esencia del alma, restablecido el gozo hacia las armonías de la razón, nuestra vida entera retorna a Dios, dando al cuerpo las armonías de la salud, sin recibir de ahí alegría: es lo que acontecerá cuando se destruya el hombre exterior y aparezca su transformación en un estado mejor."44 Así como en Platón la dialéctica implica un abandono gradual de lo sensible, y así

\footnotetext{
42 Agustín de Hipona, Carta 166, 5, 13, en Obras Completas XIa. Madrid, Biblioteca de Autores Cristianos, 1985. Traducción de Lope Cilleruelo.

43 Eugenio Trías, Lo bello y lo siniestro, cit. p. 50.

44 Agustín de Hipona, La musica, cit. VI, 12, 34.
} 
como acabamos de ver, para Agustín la ascesis virtuosa del músico es una anticipación de la separación del mundo y del encuentro con Dios ${ }^{45}$, para Trías la música permite hacer de la inhospitialidad y brutalidad originaria del mundo, un lugar humano y habitable. Y esto es posible únicamente porque los límites del mundo son convocados por la música.

Las diferencias, sin embargo, también son notables. Agustín presupone un orden trascendente del mundo y habla explícitamente de él. El papel de la música es anticipar esa trascendencia a través de la ascesis y la virtud, de modo que el músico rejuvenece su mirada sobre el mundo después del trabajo y la experiencia estética... En Trías, en cambio, esta trascendencia no está señalada más que como aquello que está más allá del límite, pero de lo que no se sabe nada o casi nada. La música tiene, aquí, como función, no sacar al sujeto del mundo, sino mostrarle sus límites, permaneciendo del lado de la frontera habitable. Esta diferencia es clave para comprender los puntos en los que pudieran llegar a separarse ambos filósofos. Sin embargo, hay que decir, por una parte, que aunque el ámbito de trascendencia queda prácticamente indefinido para Trías, tampoco es que esté negado como tal: de hecho, permanece como aquello que limita al mundo y, por otra parte, que en ambos casos la música es concebida como un arte en el que interviene una ratio o una idea y que solo con el ejercicio de ella así el mundo en su dimensión temporal adquiere su justa medida proporcional y puede convertirse en un lugar más o menos hospitalario.

La música coloca y pone en su lugar lo que ha de ir en su lugar. Sobre todo, domestica al tiempo, es decir, a la subjetividad, pues ésta quiere siempre distenderse y disolverse en el mundo de manera "mundana", en las contingencias, pero de ello solamente resulta el habitar en el desasosiego. Porque el tiempo objetivo, el tiempo de las cosas, el tiempo mundano, no es el tiempo de los hombres. "Hacer arte -señala Trías- puede definirse como ese desvelar, mostrar, sacar a luz lo topológico, mediante un trazado en virtud del cual lo que sucede es «enmarcado» en el horizonte del espacio-luz. El artista, por tanto, desvela el espacio-luz subyacente a «cualquier cosa», a «cualquier evento del mundo». No funde el arte con la vida, matando al arte; sino que toma la vida tal como se ofrece, como se da y, en exposición ultrarrápida, desvela el ámbito o espacio-luz en el cual se puede mostrar su verdad."46 Hacer arte, ser artista, significa emprender la búsqueda de los límites del mundo. La música, en ese sentido, tanto para Trías como para Agustín será la respuesta a una búsqueda de sentido, una de las vías de respuesta a la gran pregunta humana expresada en la agustiniana inquietudo cordis, provocada por la insuficiencia del mundo, por la parquedad de los bienes que se nos ofrecen, por la inhospitalidad, para decirlo con trías del estatuto originario del mundo en su contingencia. La música, así, evita que nos disolvamos en tiempo y que, aunque sea por momento, experimentemos el mundo con oídos de eternidad.

45 Sobre este punto en específico, Robert Forman ha puesto en claro ya las relaciones entre logos, música y orden, a partir de señalar las diferencias entre los modos bajo los cuales la música puede ser comprendida, y señalando que no en todos aparece el logos como instancia verdaderamente configuradora lo que, en última instancia, da fundamento a las distinciones agustinianas entre música como arte liberal y música de uso por una parte, y entre músico y cantor, por otra. Cfr. Forman, Robert J., "Augustine's Music: 'Keys' to the Logos" en La Croix, Richard (ed.) Augustine on Music: An Interdisciplinary Collection of Essays, Lewiston NY, E. Mellen Press, 1988, pp. 17-27.

46 Eugenio Trías, Los límites del mundo, cit. p. 341. 


\section{Referencias bibliográficas}

Agustín de Hipona. Cartas. Obras Completas XIa. Madrid, Biblioteca de Autores Cristianos, 1985. Traducción de Lope Cilleruelo.

Agustín de Hipona. Confesiones. Obras Completas II. Madrid, Biblioteca de Autores Cristianos, 2005. Traducción de Ángel Custodio Vega.

Agustín de Hipona. La doctrina cristiana. Obras Completas XV. Madrid, Biblioteca de Autores Cristianos, 1957. Edición preparada por Balbino Martín Pérez.

Agustín de Hipona. La música. Obras Completas XXXIX. Madrid, Biblioteca de Autores Cristianos, 1987. Traducción de Alfonso Ortega.

Agustín de Hipona. La naturaleza del bien. Obras Completas III. Madrid, Biblioteca de Autores Cristianos, 2009. Traducción de Mateo Lanseros O.S.A.

Agustín de Hipona. El orden. Obras Completas I. Madrid, Biblioteca de Autores Cristianos, 1946. Traducción de Victorino Capanaga.

Agustín de Hipona. ¿Qué es el tiempo? Libro XI de las Confesiones. Madrid, Editorial Trotta, 2011. Edición bilingüe y traducción de Agustín Corti.

Agustín de Hipona. La trinidad. Obras Completas V. Madrid, Biblioteca de Autores Cristianos, 1985. Traducción de Luis Arias.

Ando, C. "Augustine on Language" en Revue des Études Augustiniennes, v.40, 1994, pp. 45-78.

Arnou, R. Le désir de Dieu dans la philosophie de Plotin. Paris, Librairie Félix Alcan, 1920.

BARJAu, E. "La música en la obra de E. Trías" en Jacobo Muñoz y Fco. José Martín (eds.) La filosofía del límite. Debate con Eugenio Trías. Madrid, Biblioteca Nueva, 2005, pp. 237-255.

Chrétien, J.-L. Saint Augustin et les actes de parole. Paris, Presses Universitaries de France, 2008.

JACKSON, B.D. "The Theory of Signs in St. Augustine's De doctrina christiana" en Revue d'Etudes Augustiniennes et Patristiques, v.15 (n.1-2), 1969, pp. 9-49.

Kirwan, Ch. "Augustine's Philosophy of Language” en Stump, E. \& Kretzmann N. (eds.), The Cambridge Companion to Augustine, Cambridge, Cambridge University Press, 2001, pp. 186-204.

Forman, R.J. “Augustine's Music: 'Keys' to the Logos” en La Croix, R. (ed.) Augustine on Music: An Interdisciplinary Collection of Essays, Lewiston NY, E. Mellen Press, 1988, pp. 17-27.

GARCÍA BACCA, J.D. Introducción general a las Enéadas. Buenos Aires, Editorial Losada. 1948.

Krakowski, E. L'Esthétique de Plotin et son influence. L'Esthétique de Plotin et la doctrine de saint Agustin. París, 1929.

La Croix, R. (ed.). Augustine on Music: An Interdisciplinary Collection of Essays, Lewiston NY, E. Mellen Press, 1988.

Lacoste, J.-Y. Experiencia y absoluto. Cuestiones que se encuentran en discusión sobre la humanidad del hombre. Salamanca, Ediciones Sígueme, 2010. Traducción de Tania Checchi. 
LóPez QuinTÁs, A. "La música, símbolo de la Trinidad. Consideraciones a propósito de una obra extraordinaria” en Pensamiento. Revista de investigación e información filosófica, v.54 (n.210), 1998, pp.443-447.

MuÑOz, J. "Experimentum mundi (Nota sobre la ontología trágica de Eugenio Trías)" en Jacobo Muñoz y Fco. José Martín (eds.) La filosofía del límite. Debate con Eugenio Trías. Madrid, Biblioteca Nueva, 2005, pp.53-66.

PAz, O. El arco y la lira. México, Fondo de Cultura Económica, 1982.

RoBIn, L. La théorie platonicienne de l'amour. Paris, Presses Universitaires de France, 1964

Reyes, A. La experiencia literaria. México, Fondo de Cultura Económica, 1983.

TRÍAS, E. Lo bello y lo siniestro. Barcelona, Seix Barral, 1982.

TríAs, E. El canto de las sirenas. Argumentos musicales. Barcelona, Galaxia Gutenberg, 2007.

TríAs, E. La imaginación sonora. Argumentos musicales. Barcelona, Galaxia Gutenberg, 2010.

TríAs, E. Los límites del mundo. Barcelona, Ediciones Destino, 2000.

TríAs, E. Lógica del límite. Barcelona, Destino, 1991.

UÑA SuÁREZ, A. "Pulchritudinis leges. Interioridad y orden en el ejemplarismo estético de san Agustín” en La Ciudad de Dios, v.208, 1995, pp.849-882.

ZARA, V. "Music and Architecture between the Middle Ages and the Modern Age- Critical History of an Idea" en Acta Musicologica, v.77, n.1, 2005.

Diego I. Rosales Meana

Investigador del Centro de Investigación Social Avanzada

Querétaro, México

diego.rosales@cisav.org 